\title{
Spiro-prorocentrimine, a novel macrocyclic lactone from a benthic Prorocentrum sp. of Taiwan
}

\author{
Chung-Kuang Lu, ${ }^{\mathrm{a}, \mathrm{c}}$ Gene-Hsiang Lee, ${ }^{\mathrm{b}}$ Rang Huang ${ }^{\mathrm{a}}$ and Hong-Nong $\mathrm{Chou}^{\mathrm{c}, *}$ \\ anstitute of Oceanography, National Taiwan University, Taipei, Taiwan 10617, ROC \\ ${ }^{\mathrm{b}}$ Instrument Center, College of Science, National Taiwan University, Taipei, Taiwan 10617, ROC \\ ${ }^{\mathrm{c}}$ Institute of Fisheries Science, National Taiwan University, Taipei, Taiwan 10617, ROC
}

Received 9 November 2000; revised 6 December 2000; accepted 15 December 2000

\begin{abstract}
Spiro-prorocentrimine, $\mathrm{C}_{42} \mathrm{H}_{69} \mathrm{NO}_{13} \mathrm{~S}$, is a polar lipid-soluble toxin isolated from a laboratory-cultured benthic Prorocentrum species of Taiwan, crystallized in methanol. X-ray diffraction analysis of the compound revealed a spiro-linked cyclic imine with the ortho, para-disubstituted 3 '-cyclohexene in addition to its macrolide skeleton. ${ }^{13} \mathrm{C}$ and ${ }^{1} \mathrm{H}$ NMR signals were then assigned accordingly. This is the first compound of this group of marine toxins with a clear stereochemistry. C) 2001 Elsevier Science Ltd. All rights reserved.
\end{abstract}

From species of Prorocentrum, diarrhetic shellfish poisoning (DSP) toxins, such as okadaic acid (OA) and its congeners, DTX-1 and DTX-2, together with their esterified elements, have been reported elsewhere. ${ }^{1}$ In addition to this polyether skeleton having some adjacent ether rings spirally-arranged, bioactive macrocyclic lactones were also reported in various species of Prorocentrum. $^{2}$ Recently more bioactive alkaloids were reported from the marine shellfish ${ }^{3}$ and dinoflagellate. ${ }^{4}$ Some of them, gymnodimine and pinnatoxins contain an imine moiety. In an attempt to elucidate the possible toxic algae responsible for the sporadically occurring shellfish and fish poisonings in Taiwan, various species of planktonic and benthic dinoflagellates in the local waters were isolated and maintained as unialgal cultures in the laboratory. Toxic species and fractions were identified by the mouse and brine shrimp larvae toxicity assay. Prorocentrum lima PL01 and one unknown species PM08 belonging to the same genus were studied in this report for their toxic components according to their mouse toxicities from the i.p. injection of the chloroform and methanol extracts.

Both Prorocentrum sp. PM08 and P. lima PL01 are benthic strains which can be isolated from the wash-off epiphytes of seaweeds growing in the coral reef of Taiwan. They were cultured in $\mathrm{K}$ nutrient-enriched

Keywords: Prorocentrum; marine toxin; spiro-prorocentrimine; X-ray crystallography.

* Corresponding author. seawater medium ${ }^{5}$ at $25^{\circ} \mathrm{C}$ with continuous aeration and $14 \mathrm{~L} / 10 \mathrm{D}$ illumination. Algal cells $\left(9.3 \times 10^{9}\right.$ and $1.9 \times 10^{9}$ cells, respectively) harvested from $100 \mathrm{~L}$ of the 4 week culture were extracted with methanol. After partial solvent evaporation, the aqueous methanol was fractionated into $n$-hexane, chloroform and $n$-butanol solutions. Both chloroform and $n$-butanol fractions showed toxicity and were subjected to further column separations. From chloroform extracts of P. lima PL01, OA, DTX-1 and their derivatives were purified by silica gel flash chromatography and subsequent $\mathrm{C} 18$ reversedphase HPLC. ${ }^{6}$ Gel permeation chromatography (LH20; $\mathrm{MeOH} / \mathrm{H}_{2} \mathrm{O}$ 7:3) of the butanol-soluble fractions of both PL01 and PM08 yielded a toxic fraction separately. Further purification of this fraction by normal phase flash column (silica gel; EtOAc/ $\mathrm{MeOH} / \mathrm{H}_{2} \mathrm{O}$ 7:3:1) and then gradient elution on reversed-phase HPLC (C18; MeCN/0.01 M NH $\mathrm{MAAc}_{4} 25: 75$ to 40:60, UV det., $210 \mathrm{~nm}$ ) yielded prorocentrolide analogs. From PL01, 4-hydroxyprorocentrolide and 14- $O$-acetyl-4-hydroxyprorocentrolide were obtained, ${ }^{6}$ and from PM08, prorocentrolide and a new macrolide $(3 \mathrm{mg})$, denoted spiro-prorocentrimine (1) were obtained as crystals in $\mathrm{MeOH}$. Mouse toxicity assay (i.p.) of $\mathbf{1}$ exhibited an $\mathrm{LD}_{99}$ of $2.5 \mathrm{mg} / \mathrm{kg}$.

Spiro-prorocentrimine 1 showed positive to Dragendorff's reagent and gave mp $230^{\circ} \mathrm{C}$ (decomposed), $[\alpha]_{\mathrm{D}}$ $-51.4^{\circ}(c, 0.28, \mathrm{MeOH}), \mathrm{UV} \lambda_{\max } 214 \mathrm{~nm}(\varepsilon, 5200)$, and IR $\left(\mathrm{BaF}_{2}\right) v_{\max } 3408,2926,1728,1645,1435,1227 \mathrm{~cm}^{-1}$. The molecular formula of $\mathbf{1}$ was found to be $\mathrm{C}_{42} \mathrm{H}_{69} \mathrm{NO}_{13} \mathrm{~S}$ by HR-FABMS $(\mathrm{m} / z$ 828.4576, calcd. for 
$\mathrm{C}_{42} \mathrm{H}_{70} \mathrm{NO}_{13} \mathrm{~S}[\mathrm{M}+\mathrm{H}]^{+}$828.4568). The strong absorption at $1227 \mathrm{~cm}^{-1}$ in the IR spectrum and the loss of $80 \mathrm{mu}$ $\left(-\mathrm{SO}_{3}\right)$ in the $\mathrm{B} / \mathrm{E}$ constant linked scan of positive FAB-MS, suggested the presence of a sulfate group.

A colorless crystal of $\mathbf{1}$, dimensions $0.30 \times 0.15 \times 0.13$ $\mathrm{mm}$, was selected for X-ray analysis. The crystallographic data were collected on a SMART CCD diffractometer with Mo $\mathrm{K} \alpha$ radiation. Structure analysis was made on a SiliconGraphics computer using the SHELXTL program. Compound 1 crystallized in the space group $P 2_{1}$, monoclinic, $a=11.0256(1), \quad b=$ 19.2705(4), $\quad c=12.5744(2) \quad \AA, \quad \beta=102.350(1)^{\circ}, \quad V=$ $2609.84(7) \AA^{3}, \quad z=2, \lambda=0.71073, \mu($ Mo K $\alpha)=0.129$ $\mathrm{mm}^{-1},(000)=1040$ and $T=295 \mathrm{~K}$. A total of 17845 reflections were collected in the range of $3.32 \leq \theta \leq$ $25.00^{\circ}$, of which 8527 unique reflections and 5729 with $I \geq 2 \sigma(I)$ were collected for the analysis. The structure was solved using the direct method and refined by full-matrix least-squares on $F^{2}$ values. Non-hydrogen atoms were refined anisotropically. Hydrogen atoms were fixed at calculated positions and refined using a riding mode. The final indices were $R=0.0859, R_{\mathrm{w}}=$ 0.1558 with goodness-of-fit $=1.076$. The structure (Fig. 1) generated by the X-ray analysis was in full agreement with the structural information derived from NMR spectra as in the following. Compound $\mathbf{1}$ has a spirolinked imine moiety, other than prorocentrolide.

The ${ }^{1} \mathrm{H}$ and ${ }^{13} \mathrm{C}$ NMR data of $\mathbf{1}$ measured in $\mathrm{CD}_{3} \mathrm{OD}$ and DMSO- $d_{6}$ are summarized in Table 1 . There were 41 signals, consisting of 4 methyls, 15 methylenes, 18 methines and 4 quaternary carbons, revealed in the ${ }^{13} \mathrm{C}$ NMR spectrum of 1 in $\mathrm{CD}_{3} \mathrm{OD}$, but all 42 carbon signals were observed in DMSO- $d_{6}$. The missing ${ }^{13} \mathrm{C}$ signal at $32.92 \mathrm{ppm}$ (in DMSO- $d_{6}$ ) in $\mathrm{CD}_{3} \mathrm{OD}$ was assigned as $\mathrm{C} 31$, the allylic methylene. The missing signal of the carbon ( $\alpha$ to the $\mathrm{C}=\mathrm{N}$ bond) was assumed a result of imine-enamine tautomerism. ${ }^{4 a}{ }^{1} \mathrm{H}-{ }^{1} \mathrm{H}$ COSY and HMQC spectra led to the elucidation of four structure fragments (H2-H6; H8-H31; H34-H36 and $\mathrm{H} 37-\mathrm{H} 38$ ) (Fig. 2). Cross-peaks from ${ }^{2,3} J_{\mathrm{CH}}$ of $\mathrm{H} 14 / \mathrm{C} 1$,
$\mathrm{H} 2 / \mathrm{C} 1, \mathrm{H} 6 / \mathrm{C} 7, \mathrm{H} 38 / \mathrm{C} 7$, and $\mathrm{H} 6 / \mathrm{C} 8$, gave support to the assignment of carbon skeleton from $\mathrm{C} 1$ to $\mathrm{C} 31$ and the methyl- and hydroxyl-substituted carbons on it. The connectivities of spirocarbon (C33) to its nearby carbons and the assignment of imine carbon (C32) were determined by the cross-peaks of $\mathrm{H} 9 / \mathrm{C} 33, \mathrm{H} 34 / \mathrm{C} 33$, $\mathrm{H} 37 / \mathrm{C} 33, \mathrm{H} 36 / \mathrm{C} 32, \mathrm{H} 37 / \mathrm{C} 32$ and $\mathrm{H} 34 / \mathrm{C} 32$ in $\mathrm{HMBC}$ experiment. The cyclic imine moiety was further confirmed by the chemical shifts $\left(\delta_{\mathrm{C}} 44.27, \delta_{\mathrm{H}} 3.43,3.58\right.$ in DMSO- $d_{6} ; \delta_{\mathrm{C}} 44.41, \delta_{\mathrm{H}} 3.69$ in $\left.\mathrm{CD}_{3} \mathrm{OD}\right)$ of $\mathrm{C} 36$, a typical nitrogen-bearing carbon. The assignment of oxycarbons: $\mathrm{C} 14$ was assigned to $\delta_{\mathrm{C}} 80.07\left(\mathrm{CD}_{3} \mathrm{OD}\right)$ as an ester-bounded carbon and a cross peak between $\mathrm{H} 14 / \mathrm{C} 1$ in HMBC; hydroxy-substituted carbons C3, $\mathrm{C} 5, \mathrm{C} 15, \mathrm{C} 21$ and $\mathrm{C} 25$ were easily distinguished from each other by the COSY cross peaks of their boundedprotons and the corresponding hydroxy-protons; a downfield shifted oxycarbon at $\delta_{\mathrm{C}} 83.27$, together with a signal at $\delta_{\mathrm{C}} 76.77$, were assigned as $\mathrm{C} 22$ and $\mathrm{C} 18$, respectively due to a NOE correlation between $\mathrm{H} 22$ / $\mathrm{H} 18$ and a pair of long range couplings ${ }^{3} J_{\mathrm{CH}}$ of $\mathrm{H} 22 /$ $\mathrm{C} 18$ and $\mathrm{H} 18 / \mathrm{C} 22$ (HMBC), that indicated an ether linkage between $\mathrm{C} 18$ and $\mathrm{C} 22$ in the six-membered ether ring; another downfield shifted ${ }^{13} \mathrm{C}$ signal at $\delta_{\mathrm{C}}$ 79.80 in DMSO- $d_{6}$ or $\delta_{\mathrm{C}} 82.70$ in $\mathrm{CD}_{3} \mathrm{OD}$ was assigned as sulfate-substituted $\mathrm{C} 19$; and then the last ${ }^{13} \mathrm{C}\left(\delta_{\mathrm{C}}\right.$ 77.67 in DMSO- $d_{6}$ or $\delta_{\mathrm{C}} 79.13$ in $\left.\mathrm{CD}_{3} \mathrm{OD}\right)$ was assigned as hydroxy-substituted C20. The NOESY spectrum gave strong NOE cross peaks for $\mathrm{H} 8 / \mathrm{H} 2$ and $\mathrm{H} 8 / \mathrm{H} 4$ in addition to $\mathrm{H} 8 / \mathrm{H} 11$ and $\mathrm{H} 8 / \mathrm{H} 6$ (Fig. 2) that were not expectable in the spatial arrangement of the crystal structure resolved from X-ray crystallography (Fig. 1). It is speculated that a different conformation from the crystal model of the macrolide moiety of $\mathbf{1}$ is preferred in DMSO solution. Strong cross peaks of $\mathrm{H} 19 / \mathrm{H} 21, \mathrm{Me} 23 / \mathrm{H} 21, \mathrm{H} 18 / \mathrm{H} 20, \mathrm{H} 18 / \mathrm{H} 22$, and $\mathrm{H} 20 /$ $\mathrm{H} 22$ in NOESY indicates that $\mathrm{H} 19$ and $\mathrm{H} 21$ are in opposite orientation to H18, H20, and H22 (Fig. 2), that agrees well with the crystal conformation (Fig. 1). The substitutions of the double bond, $\mathrm{C} 13=\mathrm{C} 14$ was determined as the $E$ form from both X-ray crystallographic analysis and NOESY experiment.
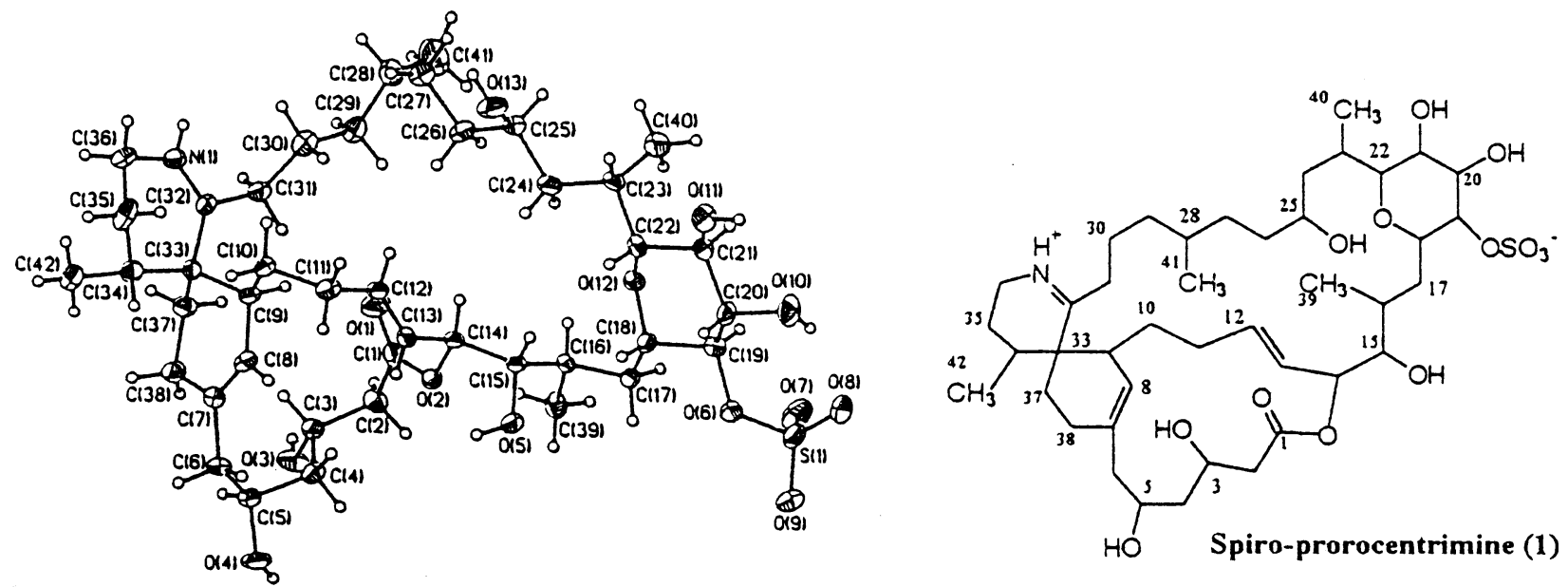

Figure 1. Computer-generated perspective drawings of the final X-ray crystallographic model of spiro-prorocentrimine (1). The thermal ellipsoids are drawn at the $30 \%$ probability level. 
Table 1. ${ }^{1} \mathrm{H}$ and ${ }^{13} \mathrm{C}$ NMR data of spiro-prorocentrimine in DMSO- $d_{6}$ and $\mathrm{CD}_{3} \mathrm{OD}$

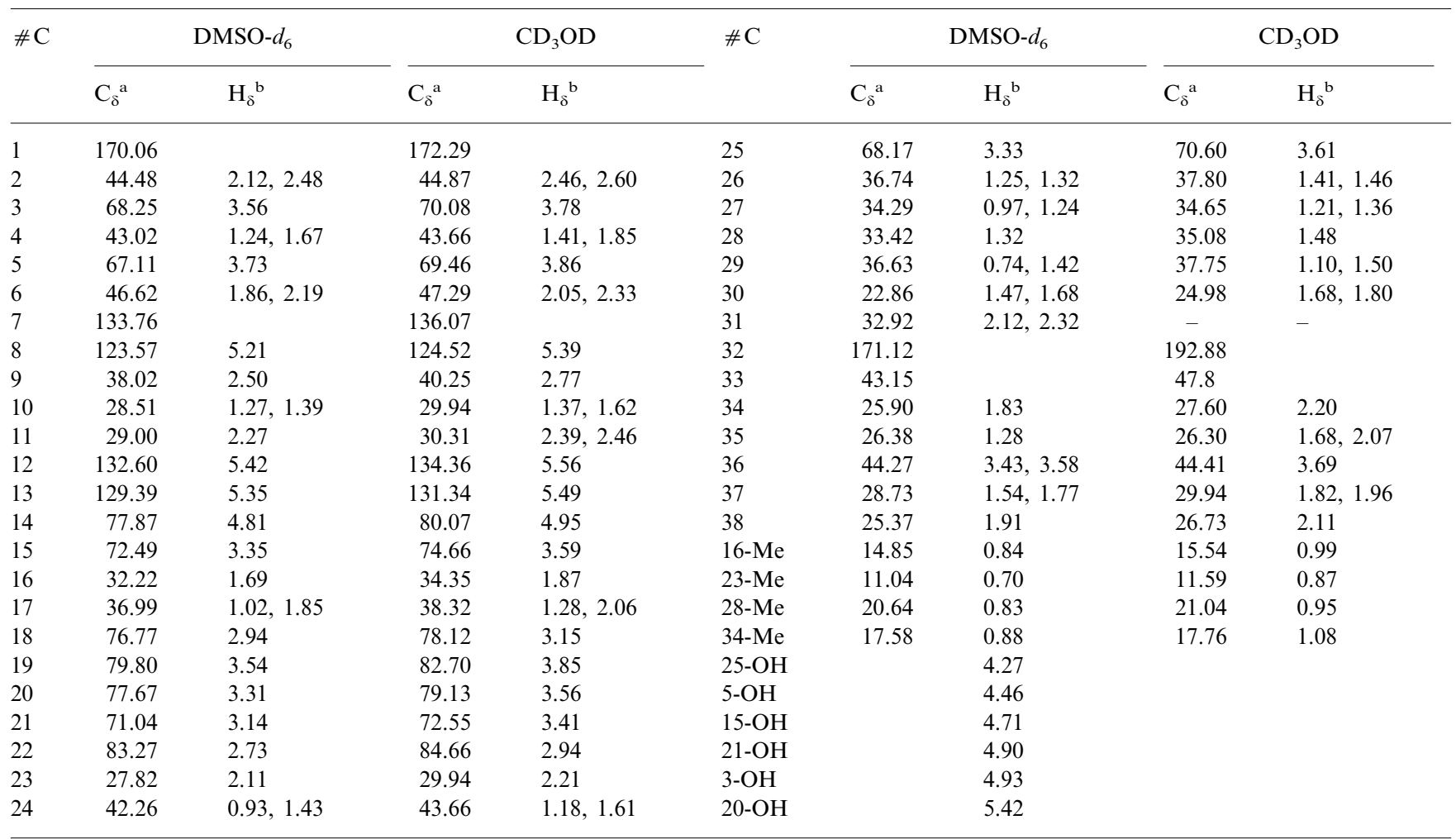

${ }^{\text {a }}{ }^{13} \mathrm{C}$ NMR chemical shifts in DMSO- $d_{6}$ taken as $\delta 39.5$ and $\mathrm{CD}_{3} \mathrm{OD}$ taken as $\delta 49.0$ (125 MHz, Bruker DMX-500).

b ${ }^{1} \mathrm{H}$ NMR chemical shifts in DMSO- $d_{6}$ taken as $\delta 2.50$ and $\mathrm{CD}_{3} \mathrm{OD}$ taken as $\delta 3.30$ (500 MHz, Bruker DMX-500).
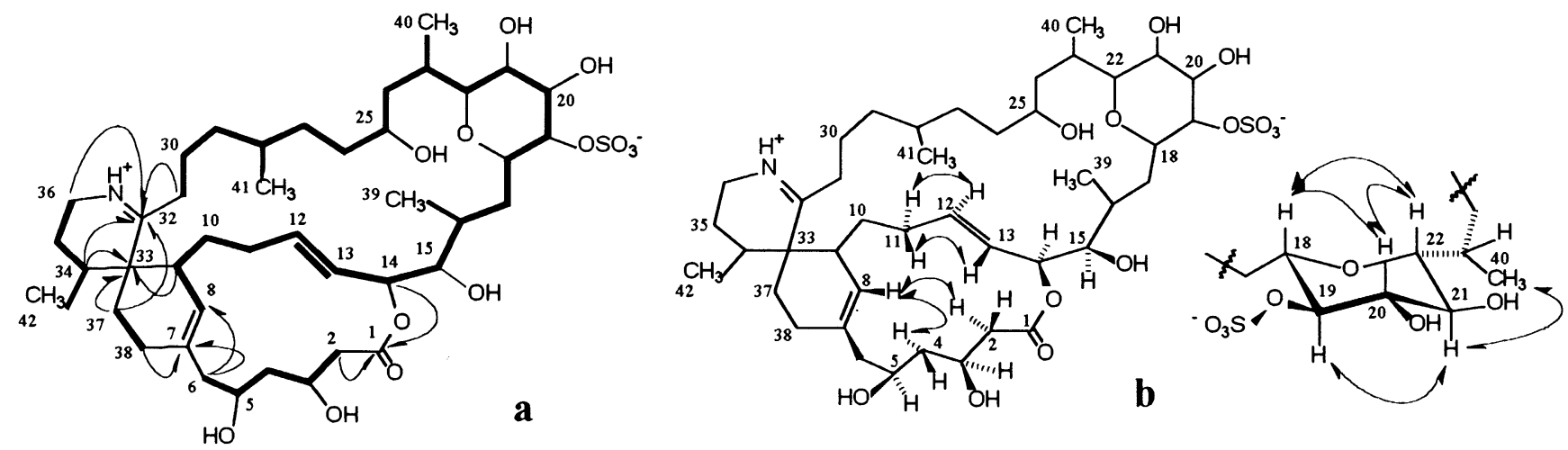

Figure 2. (a) Connectivity established by ${ }^{1} \mathrm{H}-{ }^{1} \mathrm{H}$ COSY, HMQC, and HMBC. Heavy lines indicate the connectivity assigned on the basis of ${ }^{1} \mathrm{H}-{ }^{1} \mathrm{H}$ COSY and HMQC and one-head arrows denote the selected HMBC correlation between the quaternary carbons (head) and their adjacent protons (tail). (b) Partial conformation of $\mathbf{1}$, based on NOE correlations obtained in DMSO- $d_{6}$. Two-head arrows denote the NOE correlated proton pairs.

Fragment ions at $m / z 737,645,553,641,369$ and 278 observed in the FAB B/E constant linked scan spectrum of positive ion of $\mathbf{1}$ indicated that bond cleavages occurred at the $\alpha$ and $\beta$ positions to the hydroxyl groups or at the characteristic sites of the ether ring. Similar observations were also reported in amphidinol $^{7}$ and maitotoxin. ${ }^{8}$

The spiro-linked cyclic imine with the ortho, para-disubstituted 3'-cyclohexene of compound $\mathbf{1}$ has a unique structure different from the hexahydroisoquinoline moiety of prorocentrolide, but these two toxins have a similar macrolide feature. Both compound $\mathbf{1}$ and prorocentrolide in the PM08 strain of Prorocentrum suggests that both may share some parts of the biosynthetic pathway. The spiro-linked arrangement and cyclic imine of compound $\mathbf{1}$ are not unprecedented in dinoflagellate toxins. Despite the fact that the cyclic imine moiety was considered to be the active site of this type of marine biotoxins, compound 1 exhibited much less toxicity than other known marine cyclic imine toxins, such as pinnatoxin A $(0.18 \mathrm{mg} / \mathrm{kg}),{ }^{3 \mathrm{a}}$ spirolide B $(0.25 \mathrm{mg} / \mathrm{kg}),{ }^{3 \mathrm{~b}}$ prorocentrolide $(0.4 \mathrm{mg} / \mathrm{kg}),{ }^{2 \mathrm{a}}$ and gymnodimine $(0.45 \mathrm{mg} / \mathrm{kg}){ }^{4 \mathrm{a}}$ 


\section{Acknowledgements}

We are grateful to Mrs. Shoou-ling Huang, Instrument Center, National Taiwan University, for measuring the $500 \mathrm{MHz}$ NMR spectra and Mr. Shin-Jen Wang, TsinHua University for B/E constant linked scan FAB-MS measurement. This project was supported by a grant for basic scientific research (NSC-88-2312-B-002-039) from the National Science Council of Taiwan.

\section{References}

1. Wright, J. L. C.; Cembella, A. D. In Physiological Ecology of Harmful Algal Blooms; Anderson, D. M.; Cembella, A. D.; Hallegraeff, G. M., Eds.; Springer-Verlag: Berlin, 1998; Vol. G41, pp. 427-451 and references cited therein.

2. (a) Torigoe, K.; Murata, M.; Yasumoto, T. J. Am. Chem. Soc. 1988, 110, 7876-7877; (b) Hu, T.; DeFreitas, A. S. W.; Curtis, J. M.; Oshima, Y.; Walter, J. A.; Wright, J. L. C. J. Nat. Prod. 1996, 59, 1010-1014.

3. (a) Uemura, D.; Chou, T.; Haino, T.; Nagatsu, A.; Fukuzawa, S.; Zheng, S.-Z.; Chen, H.-S. J. Am. Chem.
Soc. 1995, 117, 1155-1156; (b) Hu, T.; Curtis, J. M.; Oshima, Y.; Quilliam, M. A.; Walter, J. A.; WatsonWright, W. M.; Wright, J. L. C. J. Chem. Soc., Chem. Commun. 1995, 20, 2159-2161; (c) Hu, T.; Curtis, J. M.; Oshima, Y.; Walter, J. A.; Wright, J. L. C. Tetrahedron Lett. 1996, 37, 7671-7674; (d) Satake, M.; Ofuji, K.; Naoki, H.; James, K. J.; Furey, A. A.; McMahon, T.; Silke, J.; Yasumoto, T. J. Am. Chem. Soc. 1998, 120, 9967-9968; (e) Takada, M.; Iwastsuki, M.; Suenaga, K.; Uemura, D. Tetrahedron Lett. 2000, 41, 6425-6428.

4. (a) Seki, T.; Satake, M.; Mackenzie, L.; Kaspar, H. F.; Yasumoto, T. Tetrahedron Lett. 1995, 36, 7093-7096; (b) Cembella, A. D.; Lewis, N. I.; Quilliam, M. A. Phycologia 2000, 39, 74-76.

5. Keller, M. D.; Guillard, R. R. L. In Toxic Dinoflagellates; Anderson, D. M.; White, A. W.; Baden, D. G., Eds.; Elsevier: New York, 1985; pp. 113-116.

6. Chou, H. N.; Lu, C. K.; Hwang, R.; Quilliam, M. A. 2001, papers in preparation.

7. Satake, M.; Murata, M.; Fujita, T.; Naoki, H.; Yasumoto, T. J. Am. Chem. Soc. 1991, 103, 9859-9861.

8. Murata, M.; Naoki, H.; Matsunaga, S.; Satake, M.; Yasumoto, T. J. Am. Chem. Soc. 1994, 116, 7098-7107. 